(RESEARCH ARTICLE)

\title{
Effective microorganisms for germination and root growth in Kalanchoe daigremontiana
}

\author{
Prisa Domenico * \\ CREA Research Centre for Vegetable and Ornamental Crops, Council for Agricultural Research and Economics, Via dei \\ Fiori 8, 51012 Pescia, PT, Italy.
}

Publication history: Received on 09 October 2019; revised on 25 October 2019; accepted on 27 October 2019

Article DOI: https://doi.org/10.30574/wjarr.2019.3.3.0074

\begin{abstract}
The aim of the experiment was to evaluate the use of effective micro-organisms (EM) as promoters of root development and germination of $K$. daigremontiana plants. The 3 experimental groups in cultivation were: 1 ) group without microorganisms (CTRL), irrigated with water and previously fertilised substrate; 2) group with sugar cane molasses (ML) and fertilised substrate; 3 ) group with effective micro-organisms (EM) and fertilised substrate. The test showed a significant increase in the agronomic parameters analysed in plants treated with effective micro-organisms. In fact, all plants treated with (EM) showed a significant increase in plant height, number of leaves, vegetative and radical weight, number and weight of new shoots, leaf area. Also regarding the physiological analysis of plants there is a significant increase in the parameters analyzed in the thesis with effective micro-organisms. In particular, there was a significant increase in the chlorophyll content, in leaf net photosynthesis rate (Pn) and water use efficiency (WUE) and an equally significant reduction in transpiration (TR) and stomatological conductance (Gs). In the thesis treated with EM, the experiment also showed an increase in the percentage of seed germination and a significant reduction in the average germination time. Effective micro-organisms can be a valuable tool for grafting before planting new plants, for spraying and irrigation of crops, for reducing or eliminating completely the use of plant protection products against pathogens and diseases, during the storage of plant raw materials and to increase the biological activity of the soil.
\end{abstract}

Keywords: Succulent; Plant growth; Rhizobacteria; Rhizosphere; Ornamental plants

\section{Introduction}

Kalanchoe daigremontiana is a plant of the Crassulaceae family, native to south-east Madagascar where it grows on the hillside of Mount Androhibolava. It is a very robust plant, with an erect posture, simple stem or little branched, up to one meter high. The leaves, up to $20 \mathrm{~cm}$ long, slightly toothed at the margins, have a shiny green or bronzed upper page, while the lower one is greyish green, irregularly spotted with dark green, brown. On the edges of the leaves, between one tooth and the other, come out adventitious propagules which, falling on the ground, originate new small plants which root immediately. The flowers, grey-purple, tubular and up to $2 \mathrm{~cm}$ long, bloom by the end of winter in the adult plants. This plant reproduces forming many small helicoidal-shaped seedlings, on the edge of each of the fleshy and triangular leaves; when these seedlings fall, they effectively root even on small portions of soil. This Kalanchoe is very easy to grow, possibly in full sunlight on a fertile, but well drained substratum. It must be watered abundantly in the growing season, ie. spring-summer, while during the autumn and winter the plant is to be left almost dry. The too old plants tend to get rid of the leaves at the base, and it is good that they are periodically renewed by uprooting them. Due to its climatic collocation, the Kalanchoe daigremontiana is not particularly resistant to the cold, and it is therefore advisable to keep it at a temperature not lower than 10 degrees. However, it has been verified that the plant can easily bear even lower temperatures, around the $5{ }^{\circ} \mathrm{C}$, if not irrigated and kept in conditions of not excessive atmospheric humidity [1]. Being a short day plant, like many tropical species, cultivated in apartment, it blooms only if placed in an

\footnotetext{
${ }^{*}$ Corresponding author

E-mail address: domenico.prisa@crea.gov.it
} 
environment where it is not affected by the artificial lighting. $K$. daigremontiana could be a plant toxic and harmful to the native flora and fauna $[2,3,4,5]$ and there is also evidence that it can modify some soil properties [6], but its effects on the cycle of elements such as $\mathrm{C}, \mathrm{N}$ and $\mathrm{P}$ are still unknown.

Effective micro-organisms are a commercial microbial selection containing a mixture of coexisting beneficial microorganisms collected from the natural environment.

This selection was developed at the University of Ryukyus, Japan, in early 1980 by Prof. Dr. Terou Higa. About 80 different microorganisms are able to positively influence the decomposing organic substance in such a way as to transform it into a process of "promoting life".

The main species involved in EM include [7,8]:

- Lactic acid bacteria - Lactobacillus plantarum, L. casei, Streptoccus lactis;

- Photosynthetic bacteria - Rhodopseudomonas palustrus, Rhodobacter spaeroides [9];

- Yeast - Saccharomyces cereviasiae, Candida utilis;

- Actinomycetes - Streptomyces albus, S. griseus;

- Fermenting fungi - Aspergillus oryzae, Mucor hiemalis.

EM is a fermented mixed culture of naturally occurring species of micro-organisms coexisting in an acid environment (pH less than 3,5). Micro-organisms in EM improve crop health and yield by increasing photosynthesis, producing bioactive substances such as hormones and enzymes, accelerating the decomposition of organic materials and controlling soil diseases. Effective micro-organisms can be used as herbal insecticides to control insects and pathogenic microorganisms and can also be used as plant growth inducers. Soil micro-organisms have an important influence on soil fertility and plant health. EMs interact with the soil-plant ecosystem by controlling plant pathogens and disease agents, solubilising minerals, increasing plant energy availability, stimulating the photosynthetic system, maintaining the microbiological balance of the soil, fixing biological nitrogen [10]. A characteristic of this mixture is the coexistence of aerobic and anaerobic micro-organisms. After Higa's research in Japan [7], the characteristics of EM have been studied in many countries. Studies have shown positive effects of the application of EM on soils and plants on soil quality and nutrient supply [11], plant growth $[12,13,14]$, crop yield $[15,11]$ and crop quality $[16,17,18]$. However, in some studies no positive effects were found $[10,19,20]$.

The beneficial effects of micro-organisms introduced with the application of composts, animal manure and compost tea are often short lived leaving crop plant exposed to soil associated conditions. On application, EM mixtures are also subjected to the same conditions in the soil environment. However, the main advantage the effective microorganisms have over natural organisms in organic amendments is that in EM, beneficial micro-organisms are in much greater numbers, optimally-balanced populations when introduced. They would therefore persist in the soil environment for a much longer time enough to bring about the beneficial effects. Studies have shown that, not only does the use of effective micro-organisms in agricultural soil suppress soil-borne pathogens, but also increases the decomposition of organic materials and consequently the availability of mineral nutrients and important organic compunds to plants [21]. In addition, EM enhances the activities of beneficial indigeneous micro-organisms, for example mycorrhizae which fix atmospheric nitrogen thereby supplementing the use of chemical fertiliser and pesticides. Improvement in soil fertility has significant positive effect on plant growth, flowering, fruit development and ripening in crops [22].

In this study, the possibility of using effective micro-organisms (EM) as root growth and development improvers in $K$. daigremontiana plants was evaluated.

\section{Material and methods}

\subsection{Greenhouse experiment and growing conditions}

The experiments, which began in early April 2019, were conducted in the CREA-OF greenhouses in Pescia (Pt), Tuscany, Italy $\left(43^{\circ} 54^{\prime} \mathrm{N} 10^{\circ} 41^{\prime} \mathrm{E}\right)$ on plants of Kalanchoe daigremntiana (Figure 1). The plants were placed in pots $\varnothing 12 \mathrm{~cm} ; 60$ tense plants, divided into 3 replicas of 20 plants each. All plants were fertilized with a controlled release fertilizer ( $3 \mathrm{~kg}$ m-3 Osmocote Pro® 6 months with 190 g/kg N, 39 g/kg P, 83 g/kg K) mixed with the growing medium before transplanting. The 3 experimental groups in cultivation were: 
- group without micro-organisms (CTRL), irrigated with water and previously fertilised substrate;

- group with sugar cane molasses (ML) and fertilised substrate;

- group with effective micro-organisms (EM) and fertilised substrate, dilution 1:100 (1L of EM inoculum dilution 1:100 was used for each 10L of peat, same proportion for the control thesis where only water was used).

The same proportion was also applied to the treatment with sugar cane molasses alone. During the experiment, 4 treatments with EM and molasses were carried out. The plants were watered 3 times a week and cultivated for 6 months. Plants were irrigated by drip irrigation. Irrigation was triggered by a timer whose schedule was adjusted weekly according to climate condition and leaching fraction. On September 20, 2019, the leaves number, the vegetative and radical weight, the number and weight of new shoots, the leaf area, seed germination and average germination time were recorded. Ten days before the destructive analysis, the chlorophyll content (FieldScout CM 1000 Chlorophyll Meter; SPAD index was measured on two leaves of each plant (360 measurements per treatment), net photosynthesis $(\mathrm{Pn})$, transpiration (Tn) and water use efficiency (WUE) (LI-6400XT Portable Photosynthesis System) were evaluated.

\subsection{Statistics}

The experiment was carried out in a randomized complete block design. Collected data were analysed by one-way ANOVA, using GLM univariate procedure, to assess significant $(P \leq 0.05,0.01$ and 0.001$)$ differences among treatments. Mean values were then separated by LSD multiple-range test $(P=0.05)$. Statistics and graphics were supported by the programs Costat (version 6.451) and Excel (Office 2010).

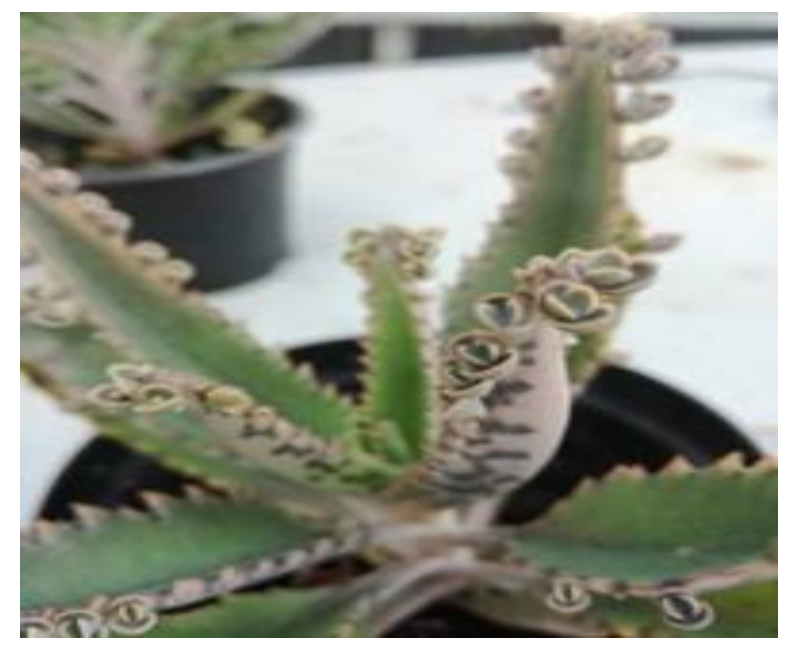

Figure 1 Details of the Kalanchoe daigremontiana plant

\section{Results}

\subsection{Plant growth}

The test showed a significant increase in the agronomic parameters analysed in plants treated with effective microorganisms. In fact, all plants treated with (EM) (Table 1) showed a significant increase in plant height (Figure 2), number of leaves, vegetative and radical weight (Figure 3B), number and weight of new shoots (Figure 3A), leaf area. In Kalanchoe daigremontiana, the height of the plants was $17.62 \mathrm{~cm}$ (EM), compared to $15.98 \mathrm{~cm}(\mathrm{ML})$ and $15.80 \mathrm{~cm}$ (CTRL). For the number of leaves, 17.42 (EM), 13.42 (ML) and 11.52 (CTRL) were found. There was a significant increase in vegetative biomass in (EM) 96.34 and $76.50 \mathrm{~g}(\mathrm{ML})$, compared with $61.48 \mathrm{~g}$ in the untreated control. The same trend applies to the root weight $54.74 \mathrm{~g}$ in (EM), $41.24 \mathrm{~g}$ in (ML) and $38.47 \mathrm{~g}$ (CTRL). The thesis with effective micro-organisms then showed a significant increase in the number of new shoots, 110.58 (EM) versus 87.42 (ML) and 70.08 in the untreated control. Also for the weight of the new shoots there is a significant increase in the treatment with (EM) 1.17 $\mathrm{g}$, against $0.76 \mathrm{~g}$ of (ML) and $0.57 \mathrm{~g}$ of the control. There was also a significant increase in leaf area in the thesis with EM, $250,33 \mathrm{~cm}^{2} \mathrm{pt}^{-1}$, compared to $197.11 \mathrm{~cm}^{2} \mathrm{pt}^{-1}$ (ML) and $194.56 \mathrm{~cm}^{2} \mathrm{pt}^{-1}$ (CTRL). 
Table 1 Evaluation of the effect of effective micro-organisms (EM) on growth of Kalanchoe daigremontiana

\begin{tabular}{|c|c|c|c|c|c|c|c|}
\hline Groups & $\begin{array}{l}\text { Height plant } \\
\text { (cm) }\end{array}$ & $\begin{array}{c}\text { Leaves } \\
\text { number }\left(n^{\circ}\right)\end{array}$ & $\begin{array}{c}\text { Veg. weight } \\
\text { (g) }\end{array}$ & $\begin{array}{c}\text { Root } \\
\text { weight } \\
\text { (g) }\end{array}$ & $\begin{array}{c}\text { Number } \\
\text { new shoots } \\
\left(n^{\circ}\right)\end{array}$ & $\begin{array}{c}\text { Weight } \\
\text { new shoots } \\
\text { (g) }\end{array}$ & $\begin{array}{l}\text { Leaf area } \\
\left(\mathrm{cm}^{2} \mathrm{pt}^{-1}\right)\end{array}$ \\
\hline CTRL & $15,80^{b}$ & $11,58^{c}$ & $61,48^{c}$ & $38,47^{b}$ & $70,08^{c}$ & $0,57^{c}$ & $194,56^{b}$ \\
\hline ML & $15,98^{b}$ & $13,42^{b}$ & $76,50^{b}$ & $41,24^{b}$ & $87,42^{b}$ & $0,76^{b}$ & $197,11^{b}$ \\
\hline EM & $17,62^{a}$ & $17,42^{\mathrm{a}}$ & 96,34 a & $54,78^{\text {a }}$ & 110,58 a & 1,17 a & 250,33 a \\
\hline ANOVA & $* * *$ & $* * *$ & $* * *$ & $* * *$ & $* * *$ & $* * *$ & $* * *$ \\
\hline
\end{tabular}

One-way ANOVA; n.s. - non significant; ${ }^{* * *},{ }^{* * *}$ - significant at $\mathrm{P} \leq 0.05,0.01$ and 0.001 , respectively; different letters for the same element indicate significant differences according to Tukey's (HSD) multiple-range test $(\mathrm{P}=0.05)$

Also regarding the physiological analysis (Table 2) of plants there is a significant increase in the parameters analyzed in the thesis with effective microorganisms. In particular, there was a significant increase in the chlorophyll content, 12.55 (EM) compared to 11.11 (ML) and 10.12 of the untreated control. In the thesis treated with effective microorganisms, there is also a significant increase in Leaf net photosynthesis rate (Pn) and Water use efficiency (WUE) and an equally significant reduction in transpiration (TR) and stomatological conductance (Gs). In the thesis treated with Effective micro-organisms, the experiment also showed an increase in the percentage of seed germination and a significant reduction in the average germination time (Table 3 ).

Table 2 Evaluation of the effect of effective micro-organisms on the physiological characteristics of Kalanchoe daigremontiana

\begin{tabular}{|c|c|c|c|c|c|}
\hline Groups & $\begin{array}{l}\text { Chlorophyll } \\
\text { content } \\
\text { (spad index) }\end{array}$ & 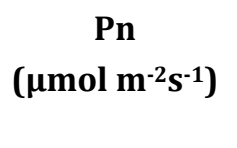 & $\begin{array}{c}\operatorname{Tr} \\
\left(\mathrm{mmol} \mathrm{m}^{-2} \mathbf{S}^{-1}\right)\end{array}$ & $\begin{array}{c}\text { Gs } \\
\left(\mathrm{mol} \mathrm{m}^{-2} \mathbf{s}^{-1}\right)\end{array}$ & $\begin{array}{c}\text { WUE } \\
(\mu \mathrm{mol} \mathrm{CO} / \\
\left.\mathrm{mmol}_{2} \mathrm{O}\right)\end{array}$ \\
\hline CTRL & $10,12^{c}$ & $9,72^{c}$ & $2,96^{b}$ & 3,03 a & $3,30 \mathrm{~b}$ \\
\hline ML & $11,11^{b}$ & $10,63 \mathrm{~b}$ & 3,23 a & 2,47 b & $3,33^{b}$ \\
\hline EM & 12,55 a & $12,10 \mathrm{a}$ & $2,00^{c}$ & $1,16^{c}$ & 6,13 a \\
\hline
\end{tabular}

ANOVA

One-way ANOVA; n.s. - non significant; ${ }^{* * *, * * *}$ - significant at $\mathrm{P} \leq 0.05,0.01$ and 0.001 , respectively; different letters for the same element indicate significant differences according to Tukey's (HSD) multiple-range test $(\mathrm{P}=0.05)$. Legend: Leaf net photosynthesis rate (Pn), chlorophyll (SPAD index) content, stomatal conductance (Gs), transpiration (Tr), water use efficiency (WUE).

Table 3 Evaluation of the effect of effective micro-organisms in the germination of Kalanchoe daigremontiana

\begin{tabular}{ccc}
\hline Groups & $\begin{array}{c}\text { Seed germination } \\
(\%)\end{array}$ & $\begin{array}{c}\text { Average } \\
\text { germination } \\
\text { time (days) }\end{array}$ \\
\hline CTRL & 87,33 & $16,00 \mathrm{~b}$ \\
ML & 88,10 & $15,00 \mathrm{~b}$ \\
EM & 94,60 & $10,00^{\mathrm{a}}$ \\
\hline ANOVA & - & $* * *$
\end{tabular}

One-way ANOVA; n.s. - non significant; ${ }^{*}, * *, * * *$ significant at $\mathrm{P} \leq 0.05,0.01$ and 0.001 , respectively; different letters for the same element indicate significant differences according to Tukey's (HSD) multiple-range test $(\mathrm{P}=0.05)$. 


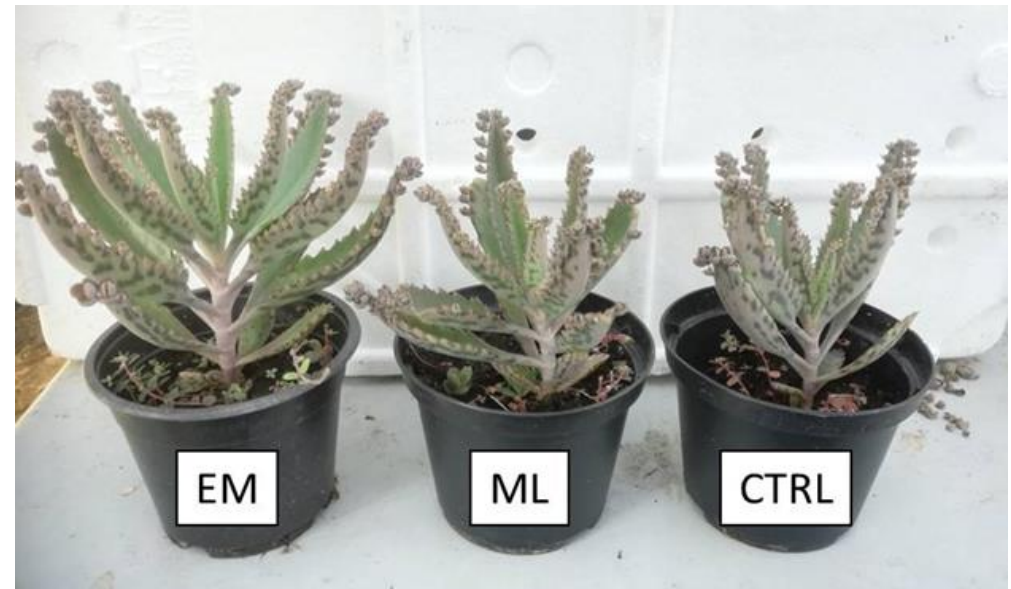

Figure 2 Effect of effective micro-organisms on growth of Kalanchoe daigremontiana. Legend: (EM) effective micro-organims; (ML) molasses; (CTRL) control.
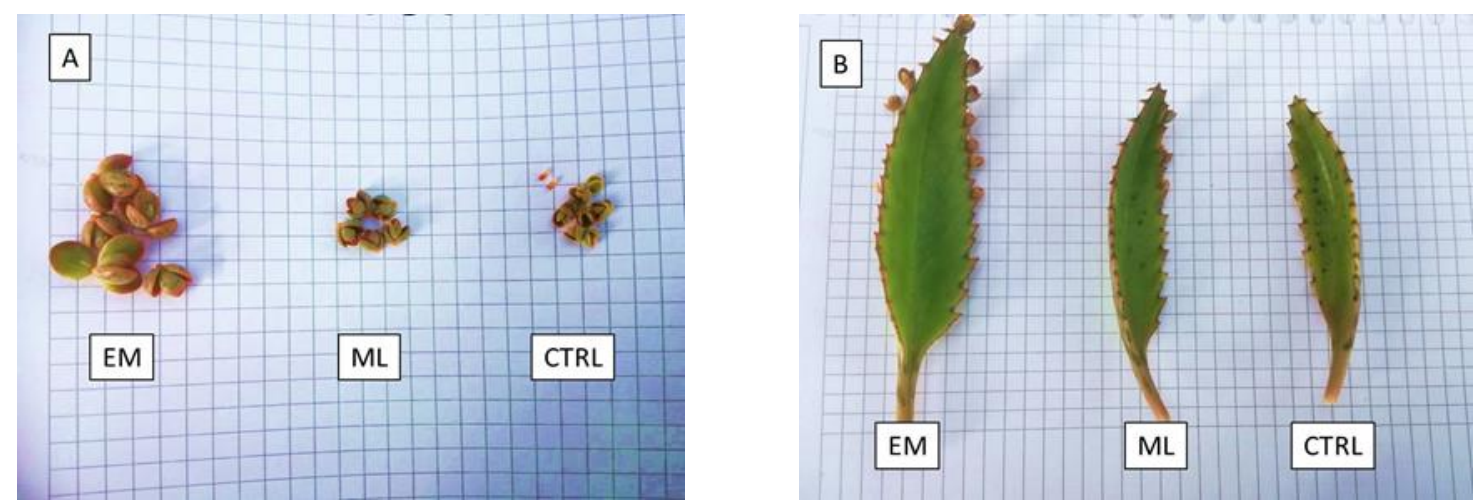

Figure 3 Effect of effective micro-organisms and molasses on growth of new shoots (A) and leaves (B).

Legend: (EM) Effective micro-organisms; (ML) molasses; (CTRL) control.

\section{Discussion}

The literature does not reveal studies on the effects of effective micro-organisms on the quality of Kalanchoe daigremontiana plants, although several works show the effects of this microbial selection on horticultural, ornamental and fruit crops $[23,24,25]$.

In this test, plants treated with (EM) showed a significant increase in plant height, number of leaves, vegetative and radical weight, number and weight of new shoots, leaf area.

The EM micro-organisms determine an increase of the radical development that influences the absorption of water and nutrients. This is reflected in the vegetative development of the plants, which grow faster and produce more new shoots. Increased root development also results in increased resistance to water and transplant stress [26].

The results show a faster growth rate of EM-treated Kalanchoe seedlings and a reduction in the possible development of fungal diseases, particularly in nurseries in the early stages of growth.

Scientists have shown that effective micro-organisms can increase fruit weight, yield and photosynthesis as also found in this experiment. In particular, EM applied with compost and manure significantly increased tomato yields, which in the third year of cultivation were comparable to those obtained with chemical fertilizers $[10,13,14]$.

The use of EM has reduced in some cases the colonization of roses from different varieties of aphids: Macrosiphum rosae L., Macrosiphum euphorbiae (Thom.), Chaetosiphon tetrarhodum (Walk.), Metopolophium dirhodum ( Walk.), Maculolachnus submacula (Walk.), Myzaphis rosarum (Kalt.), Aphis fabae Scop.[27,28]. 
Effective micro-organisms can be a valuable tool for grafting before planting new plants, for spraying and irrigation of crops, for reducing or eliminating completely the use of plant protection products against pathogens and diseases, during the storage of plant raw materials and to increase the biological activity of the soil $[13,16,17]$.

\section{Conclusion}

The test has shown how the use of effective micro-organisms can improve the quality and development of Kalanchoe daigremontiana, in particular by significantly increasing plant height, number of leaves, vegetative and radical weight, number and weight of new shoots, leaf area. There was also a marked improvement in leaf net photosynthesis rate (Pn) and water use efficiency (WUE) and an equally significant reduction in transpiration (TR) and stomatological conductance (Gs). In the thesis treated with Effective micro-organisms, the experiment also showed an increase in the percentage of seed germination and a significant reduction in the average germination time.

The application of EM in agricultural processing guarantees higher standards, with a significant reduction in production costs. The products obtained from the cultivation with Em have a high antioxidant potential, very important especially in this historical period where food also acts as a medicine.

\section{Compliance with ethical standards}

\section{Acknowledgments}

The article is part of the "Micronaturale" project: alternative techniques to synthetic chemistry for the cultivation and defence of plants.

\section{Disclosure of conflict of interest}

The author declares no conflict of interest.

\section{References}

[1] Herrera I and Nassar JM. (2009). Reproductive and recruitment traits as indicators of the invasive potential of Kalanchoe daigremontiana (Crassulaceae) and Stapelia gigantean (Apocynaceae) in a neotropical arid zone. J. Arid Environ., 73, 978-986.

[2] Mckenzie RA and Dunster PJ. (1986). Hearts and flowers: Bryophyllum poisoning of cattle. Aust. Vet. J., 63, 222227.

[3] Mckenzie RA, Franke FP and Dunster PJ. (1987). The toxicity to cattle and bufadienolide content of six Bryophyllum species. Aust. Vet. J., 64, 298-301.

[4] Nair MG, Epp MD and Burke BA. (1988). Ferulate esters of higher fatty alcohols and allelopathy in Kalanchoe daigremontiana. J. Chem. Ecol., 14, 589-603.

[5] Herrera I. (2007). Diagnóstico del Potencial Invasor de Dos Plantas Exóticas, Kalanchoe daigremontiana (Crassulaceae) y Stapelia gigantea (Apocynaceae) en una Zona Árida Tropical. Tesis. Instituto Venezolano de Investigaciones Científicas. Caracas, Venezuela. 176.

[6] Chacón N, Herrera I, Flores S, González JA and Nassar JM. (2009). Chemical, physical, and biochemical soil properties and plant roots as affected by native and exotic plants in Neotropical arid zones. Biol. Fert. Soils, 45 , 321-328.

[7] Higa T. (1991). Soil environment and microorganisms, and the health of crops. Report by the International Nature Farming Research Center, Atami, Japan. 133.

[8] Daly MJ and Stewart DPC. (1999). Influence of "Effective Microorganisms" (EM) on Vegetable Production and Carbon Mineralization-A Preliminary Investigation, Journal of Sustainable Agriculture, 14(2-3), 15-25.

[9] Condor AF, Gonzalez P and Lakre C. (2007). Effective microorganisms: myth or reality? The Peruvian Journal Biology, 14, 315-319.

[10] Olle M. (2013). Effect of efficient microorganisms on yield, quality and preservation of vegetables. In: Gardening Forum, 10-13. 
[11] $\mathrm{Xu} \mathrm{HL}$, Wang $\mathrm{R}$ and Miridha M. (2001). Effects of Organic Fertilizers and a Microbial Inoculant on Leaf Photosynthesis and fruit Yield and Quality of Tomato plants. Journal of Crop production, 3, 173-182.

[12] Prisa D. (2019). Effect of chabazitic-zeolites and effective microorganisms on growth and chemical composition of Aloe barbadensis Miller and Aloe arborescens Miller. International Journal of Agricultural Research, Sustainability, and Food Sufficiency (IJARSFS) Vol. 6(01), 315-321.

[13] Prisa D. (2018).Italian chabazitic-zeolitite and Effective microorganisms for the qualitative improvement of olive trees. Atti del Convegno di Calci (PI) 2017 Atti Soc. Tosc. Sci. Nat., Mem., Supplemento, 125, 13-17.

[14] Prisa D. (2019). Effective microorganisms for the cultivation and qualitative improvement of onion (Allium cepa L.). World Journal of Advanced Research and Reviews, 02(03), 1-7.

[15] Escano CR. (1996). Experiences on EM technology in the Philippines.

[16] Prisa D. (2019). Effective Microorganisms and Chabazitic-Zeolites For The Improvement Quality Of Echinopsis Hybrids. Asian Academic Research Journal of Multidisciplinary. 6 (2), 23-34.

[17] Prisa D. (2019). Improvement Quality and Content of Pepper and Chilli Nitrates Influenced by the Effective Microorganisms. American Scientific Research Journal for Engineering, Technology, and Sciences (ASRJETS), 53 (1), 176-181.

[18] Prisa D. (2019). Improvement quality of aubergine plants with effective microorganisms. Asian Academic Research Journal of Multidisciplinary., 6(3), 1-8.

[19] Mayer J, Scheida S, Widmera F, Fließbachb A and Oberholzer HR. (2010). How effective are 'Effective microorganisms $\AA(E M) ' ?$ Results from a field study intemperate climate. Appl. Soil Ecol.

[20] Schweinsberg MS and Torsten M. (2009). Impact of effective microorganisms and other biofertilizers on soil microbial characteristics, organic-matter decomposition, and plant growth. Journal of Plant Nutrition and Soil Science, 172(5), 704-712.

[21] Singh, DS, Chand S, Anvar M and Patra. (2003). Effect of organic and inorganic amendment on growth and nutrient accumulation by Isabgol (Plantago ovata) in sodic soil under greenhouse conditions. J. Med. Arom. Plant Sci., 25, 414-419.

[22] Lévai L, Veres SZ, Makleit P, Marozsán M and Szabó B. (2006). New trends in plant nutrition. Proceedings of 41st Croatian and 1st International Symposium on Agriculture, 435-436.

[23] Ncube L, Minkeni PNS and Brutsch 0. (2011). Agronomic suitability of effective micro-organisms for tomato production. African Journal of Agricultural research, 6, 650-654.

[24] Ncube L and Calistus B. (2012). Effects of the integrated use of effective microorganisms, compost and mineral fertilizer on greenhouse-grown tomato. African Journal of plant Science.

[25] Kengo Y and Hui-lian X. (2000). Properties and applications of an organic fertilizer inoculated with effective microorganisms. Journal of Crop production, 3(1), 255-268.

[26] Formowitz B, Elango F, Okumoto S, Müller T and Buerkert A. (2007). The role of effective microorganisms in the composting of banana (Musa ssp.) residues. J. Plant Nutr. Soil Sci., 170, 649-656.

[27] Katarzyna K. (2019). The use of effective microorganisms in the aspect of ecological protection of roses. Conference paper: Effective microorganisms in agricolture and food processing. Conference: 3rd International Scientific Conference "Human ecology".

[28] Noaema AH, Sawicka B, Pszczolkowski P and Kieltyka-Dadasiewicz A. (2018). Effective microorganisms in agriculture and food processing. Conference: 3rd International Scientific Conference "Human ecology".

\section{How to cite this article}

Prisa D. (2019). Effective microorganisms for germination and root growth in Kalanchoe daigremontiana. World Journal of Advanced Research and Reviews, 3(3), 47-53. 